\title{
Indicadores Sociais Internos e a Geração de Valor Adicionado: uma Análise da Relação do Balanço Social e da Demonstração do Valor Adicionado em Bancos Brasileiros ${ }^{1}$
}

\author{
Silvane Maria Taiarol \\ Simone Letícia Raimundini ${ }^{3}$ \\ Ariel Behr ${ }^{4}$
}

\section{RESUMO}

A divulgação de informações sobre a responsabilidade social corporativa tem aumentado substancialmente nas últimas décadas. O Balanço Social e a Demonstração do Valor Adicionado têm sido as demonstrações mais utilizadas para evidenciar tanto informações qualitativas quanto quantitativas desta natureza. O conceito que está subjacente nestas demonstrações é que o lucro de uma organização empresarial pertence a diversos grupos de interesse, e que os indicadores sociais internos e o valor adicionado distribuído estão relacionados. O objetivo desse artigo é analisar e comparar a evolução do investimento social interno, valor adicionado gerado e receita operacional e líquida bem como verificar se os investimentos sociais internos contribuem para o aumento da receita e do valor adicionado das organizações bancárias brasileiras, no período de 2000 a 2009 . Os dados foram coletados em painel e analisados qualitativamente (análise horizontal e de valores relativos) e quantitativamente (correlação e regressão). Os resultados apontam alta correlação e alta regressão do investimento social interno com a geração e a distribuição de riqueza, bem como, da receita operacional e líquida. Esse resultado corrobora com análise qualitativa, ou seja, o aumento do investimento social interno proporciona aumento no valor adicionado gerado, logo no valor adicionado distribuído aos funcionários. A principal conclusão é que os gastos com pessoal é um dos elementos para aumentar as receitas e gerar riqueza para as organizações bancárias.

Palavras-chave: Balanço Social; Demonstração do Valor Adicionado (DVA); Investimento Social Interno.

\begin{abstract}
The divulgation of information about corporate social responsibility has substantially increased in recent decades. The Balance Sheet and the Value Added Demonstration have been the mostly used reports to show both qualitative and quantitative information of this nature. The concept underlying on these statements is that the profits of a business organization owned by various interest groups, and the internal social indicators and the value added distributed are related. The aim of this paper is to analyze and compare the evolution of internal social investment, value added generated and operating and net revenue, also checking if the internal social investments contribute to revenue growth and added value of Brazilian banks, in the period from 2000 to 2009. Data were panel collected and qualitatively (horizontal analysis and relative values) and quantitatively (correlation and regression) analyzed. The results show high correlation and regression of internal social investment with generation and distribution of wealth, as well as operating and net revenue. This result confirms the qualitative analysis, in other words, the increase in internal social investment provides increases in the value added generated, then on the value added distributed to employees. The main conclusion is that the personnel expenses is one of the elements to increase revenues and generate wealth for banking organizations.
\end{abstract}

Keywords: Balance Sheet; Value Added Demonstration (DVA); Internal Social Investment; Added Value; Operating and Net Income.

\footnotetext{
${ }^{1}$ Artigo recebido em 25.10.2011. Revisado por pares em 22.11.2011 (blind review). Reformulado em 26.11.2011. Recomendado para publicação em 30.11.2011 por José Ribamar Marques de Carvalho (Editor). Publicado em 01.12.2011. Organização responsável pelo periódico: UACC/UFCG. Artigo publicado nos anais do EnANPAD 2011.

${ }^{2}$ Graduada em Ciências Contábeis - UFGRS, e-mail: siltaiarol@ hotmail.com

${ }^{3}$ Doutoranda em Administração UFRGS. Professora Assistente da Universidade Estadual de Maringá, e-mail: slraimundini@uem.br

${ }^{4}$ Doutorando em Administração UFRGS. Professor da Universidade Federal do Pampa, e-mail: behr.ariel@ gmail.com
}

REUNIR - Revista de Administração, Contabilidade e Sustentabilidade - Vol. 1, nº 2, p.82-100, Set-Dez/2011. 


\section{INTRODUÇÃO}

A necessidade das organizações serem mais transparentes aos diversos usuários das suas informações, internos ou externos, tem exigido maior divulgação dos relatórios bem como a expansão do conteúdo informacional. Informações públicas das organizações com conteúdo estritamente financeiro econômico e patrimonial têm sido complementadas com conteúdo social, especificamente da responsabilidade social corporativa (REIS e MEDEIROS, 2007).

Com esse propósito surgiu o Balanço Social (BS), documento que representa uma evolução dos relatórios contábeis, tornando-se uma importante fonte de informação para avaliar o compromisso e a transparência das organizações com a responsabilidade social. Segundo Kroetz (2000), o BS deve expor de forma clara quais as políticas praticadas e quais os seus reflexos no patrimônio, na intenção de evidenciar sua participação no processo de evolução social da organização.

Posteriormente, em complemento ao BS, surge a Demonstração do Valor Adicionado (DVA). Essa demonstração, por sua vez, apresenta a riqueza criada pelas empresas, bem como sua repartição entre os agentes sociais envolvidos (TINOCO, 2001). Conforme Santos (2003), a DVA materializa o aspecto informacional dos benefícios gerados pelas organizações dentro do contexto social em que estão inseridas.

Se, por um lado, a DVA demonstra um conjunto de informações sobre a geração de riqueza da organização e a sua repartição entre os beneficiários (acionistas, governos, financiadores externos e funcionários), por outro lado, o BS demonstra um conjunto de informações sobre os projetos, benefícios e ações sociais dirigidas aos empregados, aos acionistas e à comunidade em geral. Essa complementaridade informacional de gastos bem como de geração e distribuição de riqueza suscita o seguinte questionamento: Os investimentos sociais, especificamente nos funcionários, contribuem para a geração de riqueza e das receitas operacional e líquida das empresas?

No cenário brasileiro, as Instituições Financeiras carregam a tradição de eficiência quanto ao sucessivo aumento de seus lucros. Estas instituições, bastante verificadas na forma de Bancos Comerciais, são alvo de muito rigor normativo, e em decorrência disso geram informações de diversas naturezas sobre sua gestão. Desse modo, este artigo tem como objetivo geral analisar a evolução dos investimentos sociais internos de organizações bancárias brasileiras, no período entre os anos de 2000 a 2009. Para tanto são definidas metas, na forma de objetivos específicos, que pretendem: i) analisar e comparar a evolução dos investimentos sociais internos com a evolução do valor adicionado gerado e receitas operacional e líquida e ii) verificar se os investimentos sociais internos contribuem para o aumento da receita e do valor adicionado. A pesquisa está então delimitada às instituições bancárias brasileiras, no período de 2000 a 2009, pelos seguintes motivos: i) evitar o viés da variabilidade dos resultados que pode ocorrer quando se trabalha com diversos setores; ii) é um segmento representativo na economia nacional, que pertence ao macro segmento econômico de serviços e que tem passado por diversas mudanças institucionais e estruturais nos últimos 20 anos; iii) é uma atividade eminentemente desenvolvida por pessoas que fazem uso da tecnologia da informação; iv) disponibilidade de acesso aos BS e DVA e; v) há poucos estudos, neste segmento, sob a perspectiva da análise socioeconômica.

O artigo está organizado em cinco seções. Após esta introdução, na seção 2, é apresentada a base conceitual da pesquisa. A terceira seção compreende a metodologia. $\mathrm{Na}$ quarta seção são apresentados e discutidos os resultados da pesquisa, onde se faz uma análise

REUNIR - Revista de Administração, Contabilidade e Sustentabilidade - Vol. 1, nº 2, p.82-100, Set-Dez/2011. 
qualitativa e quantitativa (correlação e regressão). Finalmente, na seção 5, são apresentadas as conclusões do estudo, destacando que os Indicadores Sociais Internos (ISI) contribuem para a geração e distribuição de riqueza, bem como, a geração da receita líquida (RL) e receita operacional (RO) das organizações bancárias.

\section{REFERENCIAL TEÓRICO}

\subsection{Balanço Social e Demonstração do Valor Adicionado}

A elaboração e a divulgação do BS é recente, tendo seu início na década de 1960 nos Estados Unidos, na França e na Alemanha (TINOCO, 2001) e no mesmo período na América Latina (REIS e MEDEIROS, 2007). As motivações para impulsionaram as organizações desses países em apresentar essa demonstração, conforme os autores citados, foi a preocupação em divulgar suas ações realizadas fora do ambiente organizacional, principalmente relacionadas ao meio ambiente e benefícios da coletividade em geral, inclusive funcionários, aos usuários externos.

Com a demanda por esse tipo de informação aumentando, a França foi o primeiro país, em 1972, a publicar o BS e, em 1977, a criar uma lei tornando-o obrigatório para todas as empresas e estabelecimentos que possuíssem um número superior a 299 funcionários (REIS e MEDEIROS, 2007). Ainda, com a reforma do Plano Contábil de 1982, as organizações passaram também a ser obrigadas, a partir de 1983, a elaborar e a divulgar a DVA, separada do BS (TINOCO, 2001).

No Brasil, somente em 1984 foi publicado o primeiro BS, pela Nitrofértil (REIS e MEDEIROS, 2007). Também na década de 1980, a Fundação Instituto de Desenvolvimento Empresarial e Social elaborou um modelo de BS, porém, só a partir do início dos anos 1990 é que algumas organizações passaram a divulgar seus relatórios sociais (TORRES; MANSUR, 2008). Ainda, esses autores comentam que somente em 1997, com o sociólogo Herbert de Souza e o Instituto Brasileiro de Análises Sociais e Econômicas (IBASE), que a responsabilidade social corporativa e a publicação anual do BS ganharam destaque. Nesta data, o IBASE apresentou o primeiro modelo de BS, desenvolvido em parceria com técnicos, pesquisadores e representantes de instituições brasileiras públicas e privadas.

Reis e Medeiros (2007) salientam que a origem e a ênfase dada inicialmente ao BS são diferentes entre os Estados Unidos e a Europa em relação ao Brasil. Nos Estados Unidos e na Europa a principal ênfase é a influência das organizações no meio externo, evidenciando sua contribuição para a defesa dos recursos naturais e a conservação das suas condições normais. No Brasil a ênfase é o meio interno, focando salários, condições físicas e ambientais de trabalho, o bem-estar social e a seguridade social e, em segundo plano, as questões ambientais.

No que se refere à DVA, Santos (2003), comenta que é uma exime fonte de informação para as políticas de recursos humanos e as decisões de incentivos fiscais, no auxílio sobre novos investimentos e no desenvolvimento da consciência para a cidadania. Ainda, a DVA faz a conexão com o BS da organização. Contudo, a sua regulamentação e obrigatoriedade de elaboração e divulgação no Brasil é recente (instituída pela Lei $\mathrm{n}^{\mathrm{o}}$ 11.638/07). Antes desta lei, as empresas eram incentivas, pela Comissão de Valores Mobiliários, que publicassem esse demonstrativo como um quadro das Notas Explicativas.

A partir da institucionalização legal da DVA foi aprovado o Pronunciamento Técnico CPC-09 - Demonstração do Valor Adicionado. Esse pronunciamento destaca que a DVA tem

REUNIR - Revista de Administração, Contabilidade e Sustentabilidade - Vol. 1, nº 2, p.82-100, Set-Dez/2011. 
como principal objetivo expor o grau de envolvimento da organização em relação à sociedade em que está inserida e o modelo da demonstração. Todavia, a DVA não é prevista em qualquer pronunciamento do International Accounting Standards Board (IASB, 2011).

\subsection{Estudos sobre Balanço Social e Demonstração do Valor Adicionado no Brasil}

Santolin e Frey (2002) analisaram a qualidade informativa dos Balanços Sociais das organizações certificadas com o prêmio Responsabilidade Social. Os autores concluíram que as organizações pesquisadas direcionaram a maior parte dos seus esforços para o atendimento das necessidades de seus funcionários e em programas que atendessem a carência da sociedade. Ainda, os autores ressaltam a importância de dois aspectos quanto à exposição de programas sociais patrocinados pela empresa: o valor do investimento e o seu alcance. Sendo que nos Balanços Sociais analisados, foi encontrada, em maior ou menor grau, falhas desses aspectos, sendo comuns as exposições genéricas, não se revelando os valores e nem tampouco os resultados obtidos.

Bertagnolli et. al. (2006) objetivaram avaliar se as empresas estão obtendo retorno econômico sobre os investimentos nas áreas sociais e ambientais, utilizando técnicas estatísticas de regressão múltipla. Concluem que tanto a receita líquida, quanto o resultado operacional estão associados aos investimentos realizados, com destaque para os benefícios direcionados aos funcionários.

Milani Filho (2007) investigou se as empresas que se declaram socialmente responsáveis divulgam informações financeiras específicas sobre os recursos gastos em investimento social privado. $\mathrm{O}$ autor salienta que o investimento social privado é um conceito que apresenta diferentes interpretações, mas é caracterizado como uma transferência voluntaria de recursos de empresas privadas para projetos sociais, ambientais e culturais de interesse público. Os resultados da pesquisa apontaram que nem todas as organizações evidenciam tal investimento.

Ainda, o autor verificou se há diferença na dimensão desses gastos entre empresas cujos produtos estão associados à externalidades negativas e as participantes do Índice de Sustentabilidade Empresarial (ISE) da Bolsa de Valores de São Paulo. Concluiu-se que, da amostra, em torno de $12 \%$ das organizações que compõe o ISE e $72 \%$ das organizações que estão associadas à externalidades negativas não divulgam informações sobre o valor de gastos sociais, gerando dúvidas sobre a existência ou a dimensão dos investimentos à comunidade.

Souza e Pacheco (2007) buscaram verificar se o BS atende aos objetivos a que se propõe. Concluem que as informações extraídas do relatório podem ser consideradas interessantes, mas são pouco relevantes para cumprir os objetivos propostos pela literatura e, portanto, o modelo IBASE de BS precisa continuar evoluindo para que seja possível atingir tais objetivos.

Scheibe e Soutes (2008) analisaram e evidenciaram as similaridades e as divergências de três modelos de relatório para elaboração do BS. Concluíram que o modelo do Global Reporting destaca a preocupação com o meio ambiente, discriminação social e serviço voluntário; o modelo IBASE dá maior ênfase à evidenciação do retorno econômico; e o modelo do Instituto Ethos, pela abordagem e apresentação dos dados, visa a transparência e a ética, bem como, uma análise mais profunda do compromisso da organização com a sociedade.

Machado et. al. (2009) averiguaram se o volume de investimentos sociais e ambientais efetuados pelas empresas difere de um setor para outro. Constaram que os setores de comércio

REUNIR - Revista de Administração, Contabilidade e Sustentabilidade - Vol. 1, nº 2, p.82-100, Set-Dez/2011. 
e indústria dão maior importância aos investimentos relacionados aos empregados, como treinamento e benefícios.

Leite Filho e Figueiredo (2009) analisaram a relação entre os Indicadores Sociais do BS e o desempenho do Valor Econômico Adicionado (EVA) de sete instituições bancárias do Brasil. Os autores concluíram que os investimentos em responsabilidade social corporativa não explicam, de forma significativa, uma melhora no desempenho econômico-financeiro dos bancos estudados. Ainda, as regressões não apresentam relacionamento negativo entre os Indicadores Sociais e Ambientais e o EVA.

Bispo (2009) utiliza a DVA como instrumento técnico para avaliar a criação e a distribuição da riqueza gerada por organizações situadas na Zona Franca de Manaus (ZFM) com outras organizações do mesmo setor localizadas em outras regiões do Brasil. Os resultados mostraram que os incentivos fiscais concedidos às indústrias da ZFM criaram e distribuíram menos riqueza aos empregados e aos proprietários, mas os efeitos foram positivos na parcela distribuída aos governos.

Fregonesi (2009) discute a inclusão de uma linha, na DVA, para evidenciar os investimentos socioambientais realizados pelas empresas. Com essa inclusão, as organizações passariam a evidenciar em Notas Explicativas quais projetos foram incluídos, a forma de realização do investimento, quais ativos foram entregues e quais as parcerias envolvidas e, dessa forma, a sociedade poderia julgar as decisões da empresa e agir como "reguladora" do mercado.

Soares et. al. (2010) verificaram a correlação entre o faturamento da organização e os investimentos sociais e ambientais. Constataram que a correlação entre a Receita Líquida e os ISI e Indicadores Sociais Externos é muito forte e, entre as variáveis Receita Líquida e Indicadores Ambientais apresentou força moderada.

Cabe ressaltar que os estudos relatados nessa subsecção, bem como seus resultados, não são exaustivos. Contudo, foi observado que alguns estudos realizaram análise estatística e, a maioria deles, análise qualitativa descritiva dos dados. Apenas um estudo abordou instituições bancárias. Ainda, os estudos sobre o tema BS e DVA alavancaram a partir de 2006.

\subsection{Recursos Humanos e Valor Adicionado}

O BS, de acordo com Iudícibus et. al. (2010), tem quatro perspectivas: ambiental, recursos humanos, valor adicionado e, benefícios e contribuições à sociedade em geral. Essas perspectivas se referem, respectivamente, aos indicadores ambientais; indicadores sociais internos e indicadores do corpo funcional; informações relevantes quanto ao exercício da cidadania empresarial e; aos indicadores sociais externos.

Considerando o foco desta pesquisa, as perspectivas "recursos humanos" (indicadores sociais internos) e "valor adicionado" (informações relevantes quanto ao exercício da cidadania empresarial) serão tratados nesta secção.

A perspectiva "recursos humanos" também denominada de Balanço das Pessoas, busca evidenciar o relacionamento da empresa com seus funcionários, tais como: quais os benefícios, qual a diversidade, qual a desigualdade e qual a variação de emprego entre eles (FREGONESI, 2009). Assim, os ISI, conforme Soares et. al. (2010, p. 31), "evidencia informações relacionadas aos funcionários e as suas famílias". Essas informações compreendem gastos (em valores absolutos) com alimentação, encargos sociais compulsórios, previdência privada, saúde, segurança e medicina no trabalho, educação, cultura, capacitação

REUNIR - Revista de Administração, Contabilidade e Sustentabilidade - Vol. 1, nº 2, p.82-100, Set-Dez/2011. 
e desenvolvimento profissional, creches ou auxílio-creche, participação nos lucros ou resultados e outros.

Esses gastos constituem tanto um dos pilares do BS (TINOCO, 2001), como demonstram de que modo às organizações são socialmente responsáveis, isto é, não se limitam em exercer as obrigações previstas na legislação trabalhista, mas, também, no desenvolvimento profissional e pessoal de seus empregados, na melhoria das condições de trabalho e de suas relações com todos os seus colaboradores (REIS; MEDEIROS, 2007).

Além disso, os indicadores relacionados aos recursos humanos revelam a qualidade da relação organização e empregados, através do envolvimento dos funcionários na gestão da empresa, da participação nos lucros, da preparação para a aposentadoria, da participação em sindicatos da categoria, de ações visando à necessidade de redução de custos com pessoal, do nível de satisfação interna e da classificação da empresa como empregadora em pesquisas externas. Quanto à educação e a treinamento, os indicadores de desempenho social expressam o compromisso da organização com o desenvolvimento profissional de seus empregados, considerando a existência de programas de desenvolvimento e de capacitação profissional e a oferta de bolsa de estudos (REIS; MEDEIROS, 2007).

Kroetz (2000) salienta que a DVA (o valor adicionado, especificamente) faz parte da estrutura do BS. Segundo o modelo IBASE, entende-se que a DVA está inserida em uma linha do grupo "Informações Relevantes" do BS, demonstrando, percentualmente, quanto de riqueza foi destinada aos seus componentes: governo, colaboradores, acionistas, terceiros e retido. Assim, o valor adicionado total (VAT), ou seja, a riqueza gerada pela empresa; o valor adicionado distribuído aos funcionários (VADF), de acordo com Iudícibus et. al. (2010), é compreendido o total de remuneração paga, excluído o encargo com INSS; benefícios como assistência médica, alimentação, transporte, planos de benefícios e FGTS.

\section{PROCEDIMENTOS METODOLÓGICOS}

A pesquisa pode ser caracterizada como descritiva-exploratória. Pesquisas descritas, conforme Gil (2002) descreve as características de determinado evento em estudo, estabelecendo relações entre as variáveis e a natureza dessa relação. Complementando a pesquisa descritiva, Cervo e Bervian (2002) comentam que os estudos exploratórios buscam explicar as relações existentes entre as variáveis estudadas.

O loco da pesquisa é estudo de campo. Conforme Gil (2002), quando faz estudo de campo o pesquisador procura aprofundar a questão de pesquisa. Para Marconi e Lakatos (2002) a pesquisa de campo requer, em primeiro lugar, a realização de uma pesquisa bibliográfica sobre o tema e, em segundo lugar, determinação das técnicas que serão empregadas na coleta de dados e na determinação da amostra.

Assim, o campo da pesquisa foi composto por seis organizações bancárias. $\mathrm{O}$ critério para a definição dessas instituições bancárias foi: ser de origem nacional, estar entre os maiores bancos nacionais, conforme o valor do Patrimônio Líquido (BANCO CENTRAL DO BRASIL, 2010), ser um banco com carteira comercial e ter publicado o BS e a DVA no período de 2000 a 2009, por um período de pelo menos 7 anos. Assim, os bancos que atenderam esses critérios são apresentados na Tabela 1.

REUNIR - Revista de Administração, Contabilidade e Sustentabilidade - Vol. 1, nº 2, p.82-100, Set-Dez/2011. 
Tabela 1: Amostra da pesquisa e periodicidade dos dados

\begin{tabular}{|c|c|}
\hline Banco & Período \\
\hline Banco Bradesco & 2001 a 2009 \\
\hline Banco do Brasil & 2000 a 2009 \\
\hline Banco do Estado do Rio Grande do Sul & 2000 a 2009 \\
\hline Banco Itaú & 2000 a 2009 \\
\hline Banco Santander & 2001 a 2007 \\
\hline Caixa Econômica Federal & 2002 a 2009 \\
\hline
\end{tabular}

Os dados foram coletados a partir de buscas realizadas nos sítios das instituições bancárias selecionadas, buscando pelos demonstrativos contábeis e outros relatórios disponíveis. O período de coleta dos dados foi entre os meses de setembro e outubro de 2010 , cujos dados são ex post facto e coletados em painel.

Cabe destacar que os bancos Bradesco, Santander e Caixa Econômica Federal, em alguns anos, não elaboraram e/ou não divulgaram tais relatórios. Em contato via e-mail com essas empresas foram obtidos os seguintes retornos: o Bradesco informou que começou a elaborar o BS a partir de 2002 e o Santander informou que as informações divulgadas pela instituição são aquelas que estão no seu site. A Caixa Econômica Federal (CEF) não respondeu o e-mail enviado. Cabe destacar, também, que alguns dados da DVA foram obtidos a partir do banco de dados da FIPECAFI.

Os dados foram analisados qualitativamente e quantitativamente. A análise qualitativa compreendeu a descrição temporal das variáveis em estudo (ISI, VAT, VADF, RL e RO). Para essa análise os dados foram corrigidos pelo índice de inflação para que os valores fossem comparáveis e livre dos efeitos da perda do poder aquisitivo de compra.

Por sua vez, a análise quantitativa foi realizada aplicando as técnicas estatísticas correlação e regressão linear, com uso do software SPSS, versão 18. Para análise das regressões foi definido que a variável ISI é independente e as demais variáveis (VAT, VADF, RL e RO) são dependentes.

A correlação é interpretada como a relação existente entre duas variáveis, explicando a força da relação entre as variáveis (magnitude e direção) (DANCEY e REIDY, 2006). O coeficiente de correlação mais utilizado é o de Pearson, representado por $r$, com valor compreendido entre $-1<r<1$ (BISQUERRA, SARRIERA, MARTÍNEZ, 2004). Esses mesmos autores sugerem a seguinte escala de interpretação para a correlação.

\begin{tabular}{ll} 
Coeficiente & Interpretação \\
\hline$r=1$ & correlação perfeita \\
$0,80<r<1$ & muito alta \\
$0,60<r<0,80$ & alta \\
$0,40<r<0,60$ & moderada \\
$0,20<r<0,40$ & baixa \\
$0<r<0,20$ & muito baixa \\
$r=0$ & nula
\end{tabular}

Por sua vez, a regressão linear tem o propósito de descobrir o efeito de uma variável sobre outra variável. Na regressão a variável independente é também denominada de variável explicativa, pois ela prevê ou explica a variável dependente (DANCEY e REIDY, 2006).

REUNIR - Revista de Administração, Contabilidade e Sustentabilidade - Vol. 1, nº 2, p.82-100, Set-Dez/2011. 


\section{APRESENTAÇÃO E DISCUSSÃO DOS RESULTADOS}

Nesta seção são apresentados os resultados da pesquisa. Inicialmente os dados foram analisados a partir da linha de tendência de comportamento de cada uma das variáveis pesquisadas com a comparação entre os bancos. Na seção 4.2 os dados são analisados a partir da aplicação das técnicas estatísticas de correlação e regressão.

\subsection{Análise Qualitativa dos Dados}

A análise qualitativa dos dados foi realizada em valores relativos. Isto é, os valores monetários (descontados da taxa da inflação acumulada no período, utilizando o índice acumulado anual do INPC) de cada uma das variáveis foram divididos pelo respectivo número de funcionários de cada banco, em cada ano, conforme dados obtidos no BS. Isso possibilitou comparar os bancos estudados uma vez que foi obtido um índice de ISI, VAT, VADF, RL e RO por funcionário.

A primeira variável analisada foi o ISI (Gráfico 1).

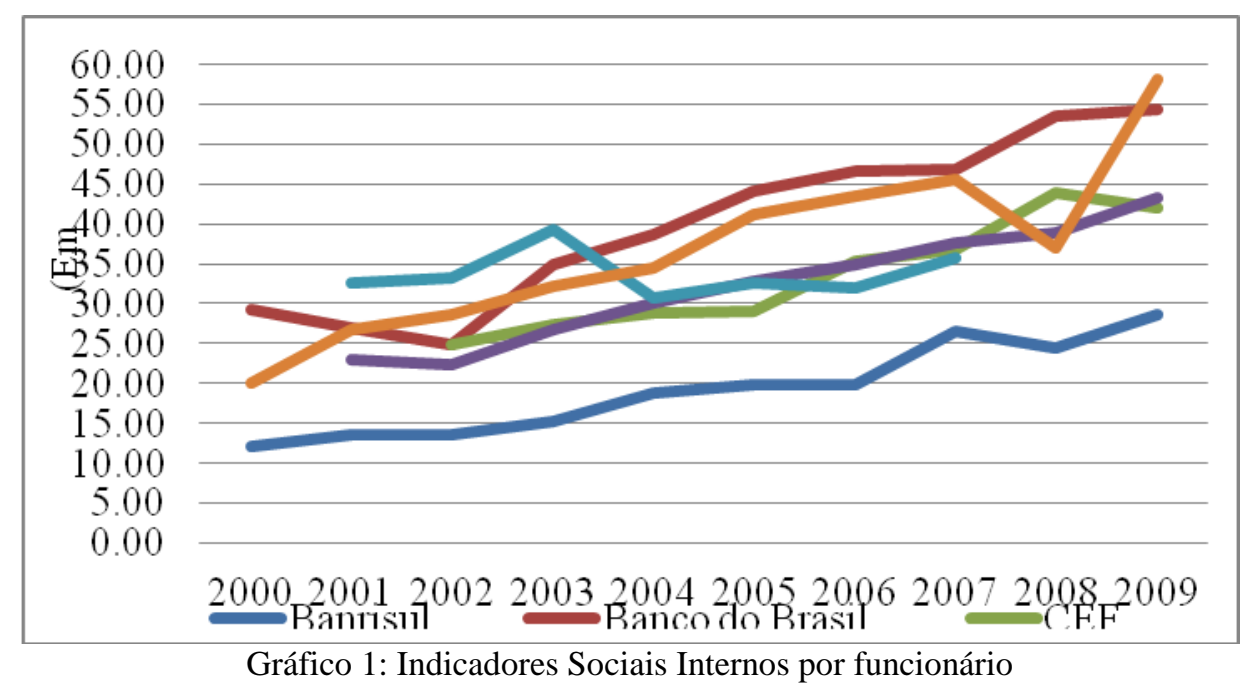

Fonte: dados da pesquisa, 2010.

Verifica-se que ISI por funcionário, de forma geral, apresentou uma evolução crescente durante o período analisado. Os resultados indicam que o Banco do Brasil é a organização bancária que mais direciona investimentos aos seus funcionários, apresentando uma média de R \$ 40.000,00 por empregado ao ano. O Santander teve uma queda brusca, de $21,88 \%$ em seus indicadores no ano de 2004 em relação ao ano 2003 e nos anos seguintes manteve um crescimento lento, mas ainda com um pequeno decréscimo em 1,42\% de 2005 para 2006. O Banco Itaú foi o que manteve uma linha crescente de investimentos, exceto no ano 2008 quando incorporou o Banco Unibanco, quando seu quadro funcional aumentou, aproximadamente, $65 \%$ e o ISI aumentou, aproximadamente, 35\%. No ano seguinte (2009) os investimentos continuam crescente, destacando como a organização bancária que mais investe por funcionário por ano (média de $\mathrm{R} \$ 58.000,00$ ). O Banrisul sempre se manteve abaixo dos demais bancos estudados, mas apresenta um crescimento gradual. Na média, o Banrisul, investe por funcionário, anualmente, aproximadamente $\mathrm{R} \$ 28.000,00$. É interessante destacar a diferença entre a empresa de maior e a de o menor ISI por funcionário em 2009: isto revela que o Banco Itaú investe nos quadro funcional, aproximadamente, 103,09\% a mais que o

REUNIR - Revista de Administração, Contabilidade e Sustentabilidade - Vol. 1, nº 2, p.82-100, Set-Dez/2011. 
Banrisul para este mesmo período.

O Gráfico 2 apresenta a evolução do comportamento referente a riqueza gerada por funcionário entre os anos 2000 e 2009.

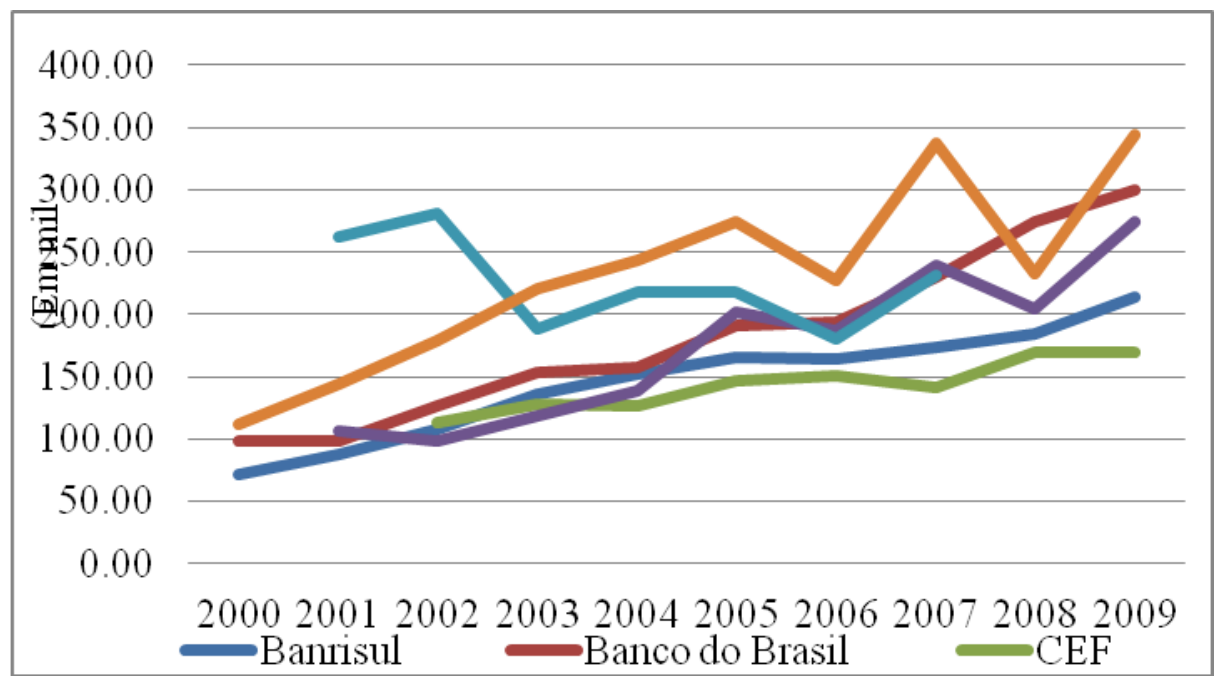

Gráfico 2: Valor Adicionado Total gerado por empregado

Fonte: dados da pesquisa, 2010.

Quanto ao VAT gerado por funcioário verifica-se que, com exceção ao Banco Santander, houve uma evolução positiva nos demais bancos. O Banco Santander aparece no ano de 2001 como aquele com maior geração de riqueza por funcionário, entretanto, em 2003 e 2006 os valores cairam bruscamente $33,08 \%$ e 17,22\%, respectivamente, em relação ao ano imediatamente anterior. Mesmo apresentado uma pequena melhora em 2007, o valor deste ano ficou aquém ao do ano de 2001. Para os bancos privados nos anos de 2006 e 2008 houve uma queda significativa na geração do VAT por empregado em relação às datas anteriores. Foi de 17,20\% e 30,92\%, respectivamente para 2006 e 2008, no Banco Itaú e de 7,69\% e 14,48\% para 2006 e 2008, respectivamente, no Banco Bradesco. Por outro lado, os bancos públicos como a CEF e o Banco do Brasil apresentaram um aumento para essa variável no mesmo período: de $2,15 \%$ e $19,92 \%$ para 2006 e 2008, respectivamente, na CEF e de $1,13 \%$ e 19,47\%, para 2006 e 2008, respectivamente, no Banco do Brasil. O Banrisul em 2000 aparece como aquele com menor riqueza gerada por empregado, contudo, apresenta um crescimento positivo ao longo do período, menos em 2006, que em relação a 2005 teve um decréscimo de 1,24\%. Em 2009 a CEF revela ser o banco com menor geração de riqueza por funcionário e, do lado oposto, o Banco Itaú que apresenta a maior geração riqueza por funcionário. A diferença entre ambos é 103,32\%.

O comportamento referente a riqueza distribuída para cada empregado no bancos pesquisados entre os anos 2000 e 2009 é demonstrado no Gráfico 3. 


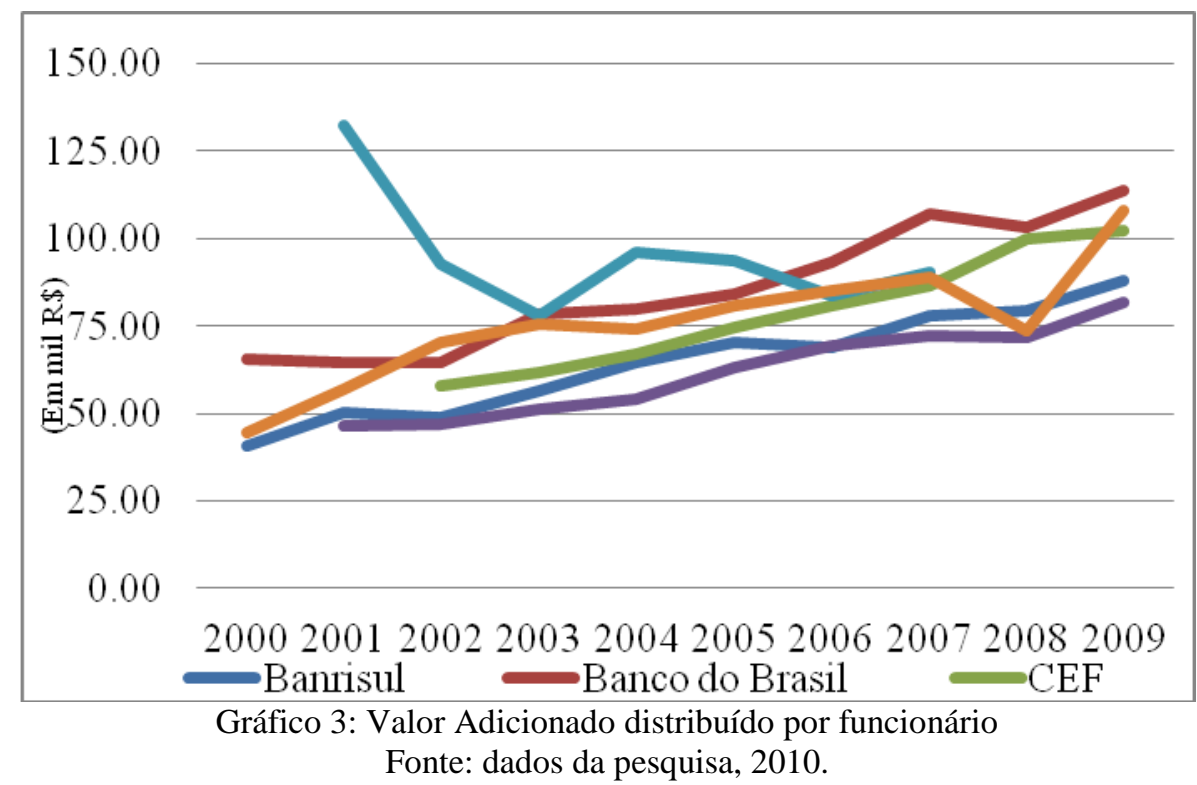

$\mathrm{Na}$ análise geral, o comportamento dos índices da VADF por funcionário se assemelham ao índice VAT por funcionário. Observa-se que os bancos pesquisados apresentaram um desenvolvimento positivo, com exceção ao Banco Santander, para o período analisado. Este banco se destaca em 2001 como aquele que mais distribuiu riqueza ao seu quadro funcional, mas nos anos seguintes apresenta um declínio quase contínuo da linha de VADF, exceto em 2004 e 2007, com crescimento de $23,15 \%$ e $7,81 \%$, respectivamente, em relação aos anos anteriores, mas não retoma a sua posição de 2001. Entretando, mesmo apresentando esta situação, o Banco Santander tem a maior média de distribuição de riqueza, com $\mathrm{R} \$$ 95.280,00 para cada funcionário. A CEF foi o único banco que apresentou crescimento contínuo na distribuição do valor adicionado aos seus empregados. O Banrisul, em 2000, é o segundo banco que menos distribuiu valor adicionado por funcionário, mas evidencia uma tendência de crescimento, exceto nos anos 2002 e 2006 onde teve uma uma pequena redução em seus índices de, respectivamente, $2,36 \%$ e $1,74 \%$ em relação aos anos anteriores. Fato também observado com o Banco Itaú, cuja redução em seus índices ocorrem em 2004 e 2008 com 1,88\% e 17,51\%, respectivamente. O Banco Bradesco foi aquele que manteve sua linha VADF sempre baixo dos demais bancos. Por outro lado, o Banco do Brasil, iniciou o período como a segunda melhor média de distribuição de riqueza ao funcionário, mas a partir do ano de 2006 tornou-se o primeiro banco com maior VADF, com a méida de R\$ 113.490,00. Destaca-se que a diferença entre o maior e o menor valor destinado ao empregado no ano de 2009 é 38,06\%, ou seja, o Banco do Brasil distribui 38,06\% a mais de riqueza ao seu empregado em relação ao Banco Bradesco.

Analisado os três gráficos tem-se o Banco do Brasil, o Banco Itaú e o Banco Santander com as maiores médias de ISI, com $\mathrm{R} \$$ 40.000,00; $\mathrm{R} \$ 36.760,00$ e; $\mathrm{R} \$ 33.780,00$, respectivamente, para cada empregado. As maiores médias de VAT por empregado são do Banco Itaú, Banco Santander e Banco do Brasil com R\$ 231.470,00; R\$ 225.570,00 e; R\$ 182.290,00, respectivamente. Finalmente, as maiores médias de VADF são do Banco Santander, do Banco do Brasil e da CEF com R\$ 95.280,00; R\$ 85.440,00 e; R\$ 78.760,00, respectivamene.

Por outro lado, as menores médias de ISI por funcionário são do Banrisul, Banco Bradesco e da CEF com $\mathrm{R} \$ 19.280,00 ; \mathrm{R} \$ 32.180,00$ e; $\mathrm{R} \$ 33.520,00$, respectivamente. As

REUNIR - Revista de Administração, Contabilidade e Sustentabilidade - Vol. 1, nº 2, p.82-100, Set-Dez/2011. 
menores médias VAT por empregado são da CEF com $\mathrm{R} \$ 143.150,00$; do Banrisul com $\mathrm{R} \$$ R\$ 145.670,00 e; do Banco Bradesco com R\$ 174.470,00. Por fim, as menores médias de VADF, por funcionário, são do Banco Bradesco com R\$ 61.890,00; do Banrisul com R\$ 64.500,00 e; Banco Itaú com R \$ 75.840,00.

A seguir é realizada uma análise horizontal para verificar o comportamentos das variáveis ISI, VAT e VADF. Segundo Santos et. al. (2006), a análise horizontal possibilita analisar a variação ocorrida de uma rubrica em relação a certo período, permitindo ao analista identifcar a evolução no tempo de determinado item. Para tanto, define-se um ano-base (2000) para a análise, sendo todos os demais calculados em relação a este.

O Gráfico 4 apresenta o comportamento referente à análise horizontal dos ISI dos bancos estudados entre os anos 2000 e 2009.

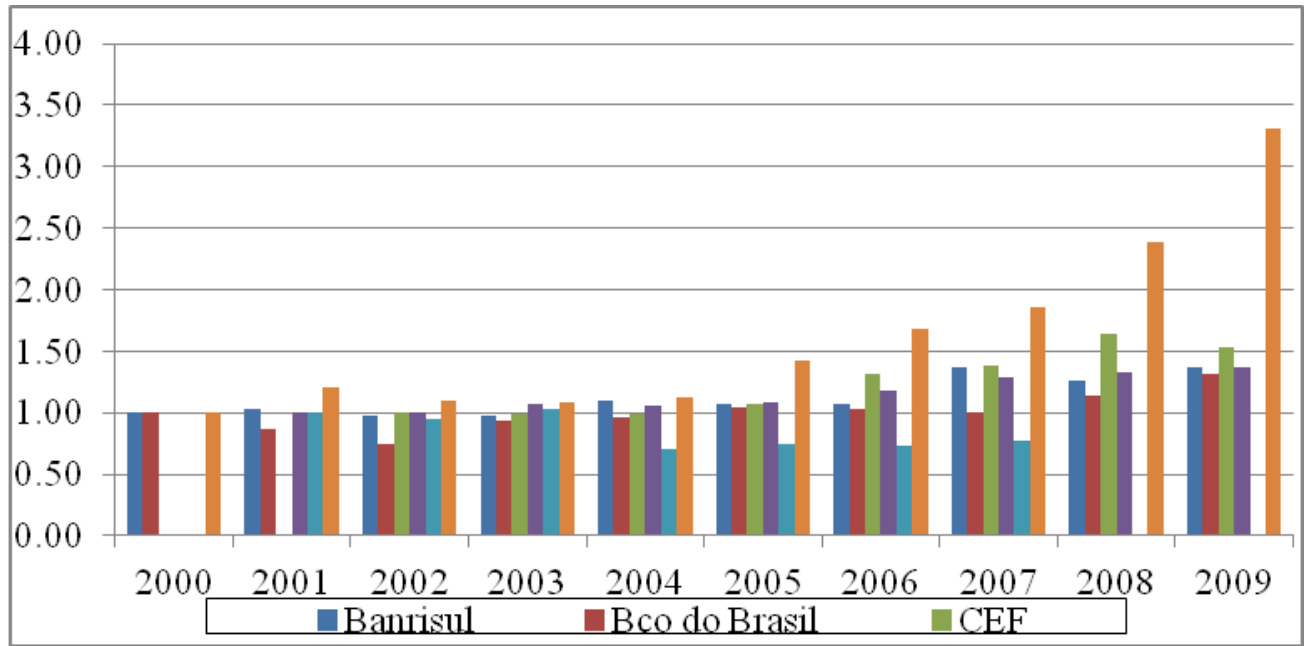

Gráfico 4: Análise Horizontal dos Indicadores Sociais Internos

Fonte: dados da pesquisa, 2010

Pode-se observar que a partir de 2006 é que ocorrem aumentos significativos nos ISI. O Banco Itaú já no ano de 2001 se sobressai em relação aos demais bancos, evidenciando como aquele que mais investiu em ISI. Entre os bancos públicos, a CEF foi a que demonstrou melhor crescimento, principalmente a partir de 2006. O Banco do Brasil no periodo de 2001 a 2004 investiu menos em seu quadro funcional e, só em 2008 é verificado um aumento significativo. O Banrisul só em 2004 começa a incrementar seus valores e a partir de 2007 fica entre as instituições que tiveram maior aumento. $\mathrm{O}$ Bradesco apresentou um aumento gradual positivo a partir de 2003. O Santander foi o que não apresentou aumento em seu índice ISI, ficando abaixo dos demais no periodo de 2004 a 2007.

A análise horizontal da riqueza gerada nos bancos pesquisados entre os anos $2000 \mathrm{e}$ 2009 é apresentado no Gráfico 5. 


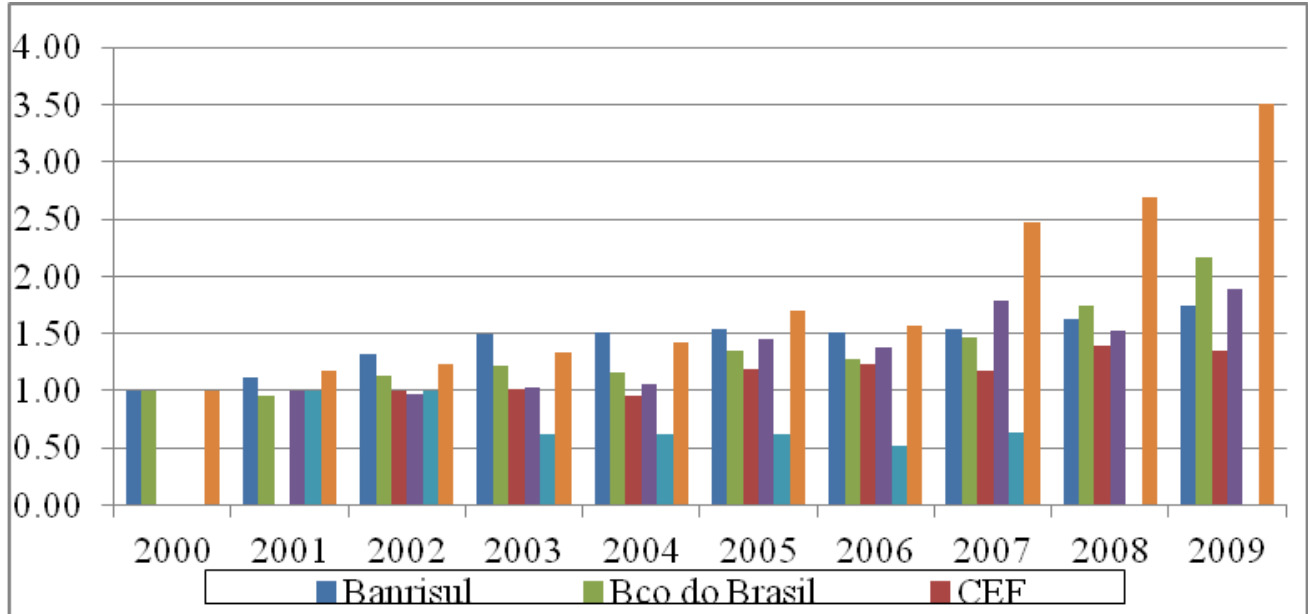

Gráfico 5: Análise Horizontal do Valor Adicionado Total gerado pelas empresas Fonte: dados da pesquisa, 2010.

Analisando o Gráfico 5 observa-se que o 2002 inicia um período de aumento no VAT para a maioria dos bancos da amostra. O Banrisul apresenta um crescimento contínuo na geração da riqueza, o qual está acima dos demais no periodo de 2002 a 2004. O Banco Itaú, a partir de 2005 está como aquele que mais cresce, disparando a partir de 2007. O Banco do Brasil apresentou oscilações, mas em 2008 e 2009 se apresenta como o segundo banco com maior crescimento no VAT. Por último, o Banco Santander, a partir de 2003, evidencia uma queda na geração da riqueza.

A análise horizontal do VADF é demonstrado no Gráfico 6.

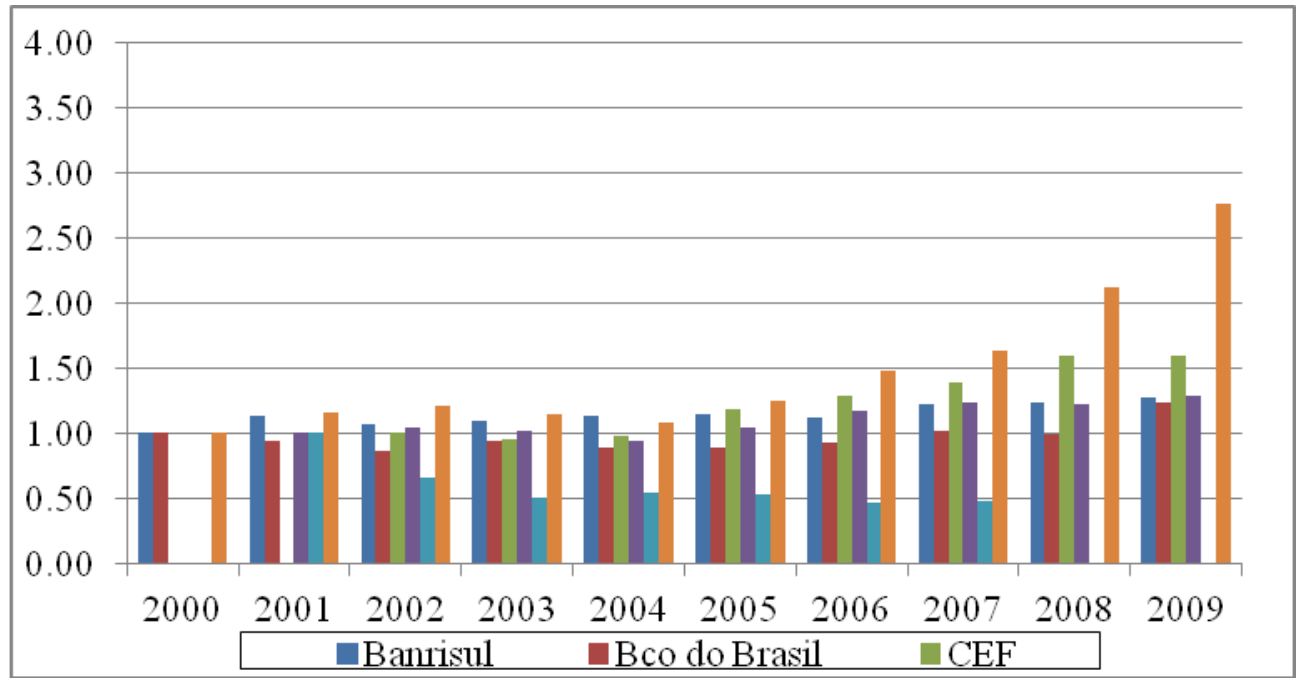

Gráfico 6: Análise Horizontal do Valor Adicionado a distribuir aos funcionários Fonte: dados da pesquisa, 2010.

$\mathrm{Na}$ análise do Gráfico 6 observa-se que a CEF e o Banco Itaú foram aqueles que apresentaram os melhores desempenhos na distribuição da riqueza aos seus empregados, principalmente a partir do ano de 2005. O Banco do Brasil obteve aumento mais expressivo somente no ano de 2009 e o Banco Santander apresentou o pior desempenho, sendo que em 2007 seu VADF correspondia a 0,48\% do valor distribuído em 2001. O Banrisul, de maneira geral, manteve uma constante na distribuição do VAT ao seu quadro funcional.

REUNIR - Revista de Administração, Contabilidade e Sustentabilidade - Vol. 1, nº 2, p.82-100, Set-Dez/2011. 
Pelos gráficos da análise horizontal verifica-se que o Banco Itaú foi o que evidenciou maior evolução nos índices ao longo do período. Neste banco, a variação positiva entre os anos de 2000 e 2009 foi de $231 \%$ nos ISI, $251 \%$ no VAT e $176 \%$ no VADF. Tal expressividade do Banco Itaú também é obervada com média geral dos índices, verificando que esse banco ficou bem acima da média entre os bancos que compõe a amostra. As médias gerais dos índices para o período apresentou uma variação positiva de $61,80 \%$ para ISI, $80,91 \%$ para VAT e $48,45 \%$ para VADF.

Por outro lado, o Banco Santander evidenciou um declínio em todos os índices ao longo do período de análise. O Bradesco apresentou uma evolução positiva dos indicadores, apresentando em 2009 uma variação de $37 \%$ nos ISI, com aumento de $88 \%$ na geração do VAT e de $28 \%$ na distribuição do VADF, comparados com o ano de 2000.

A CEF também demonstrou uma evolução positiva dos indicadores. Apresentou em 2009 uma variação positiva de 53\% no ISI, um aumento de $35 \%$ na geração do VAT e de $59 \%$ na distribuição do VADF.

O Banco do Brasil apresentou ao longo do periodo uma evolução significativa para o indicador VAT, merecendo destaque o ano de 2009 quando os três indicadores apresentaram uma alavancagem. No período 2000 a 2009, o aumento no ISI foi de 32\%; $116 \%$ no VAT e de $23 \%$ no VADF. Finalmente, o Banrisul também demonstrou uma evolução positiva para os indicadores, apresentando em 2009 uma variação de 38\% nos ISI, com aumento de $75 \%$ no VAT e de $27 \%$ no VADF.

\subsection{Análise das Correlações e Regressões}

Nessa seção os dados da amostra serão analisados a partir da correlação e regressão. Inicialmente foi calculada a correlação de Pearson para identificar a relação de dependência ou não entre as variáveis e sua análise foi realizada a partir da escala de interpretação sugerida por Bisquerra, Sarriera e Martínez (2001). A Tabela 2 sumariza a correlações obtidas.

\begin{tabular}{cccccc}
\multicolumn{5}{c}{ Tabela 2: Matriz de Correlação } \\
\hline ISI & VAT & VADF & RL & RO \\
\hline ISI & 1,000 &, $950 * *$ &, $982 * *$ &, $782^{* *}$ &, $707 * *$ \\
VAT & & $1,000 \mathrm{a}$ &, $921 * *$ &, $621^{* *}$ &, $816^{* *}$ \\
VADF & & 1,000 &, $839 * *$ &, $638^{* *}$ \\
RL & & & $1,000 \mathrm{a}$ &, $348^{* *}$ \\
RO & & & 1,000 \\
\hline \multicolumn{7}{c}{ Fignificância no nível de 0,001} \\
\end{tabular}

A matriz de correlação demonstra que as variáveis estão correlacionadas positivamente, o que significa que se o ISI aumentar, o mesmo vai ocorrer com o VAT, o VADT, a RL e o RO. Como a variável independente é o ISI, observa-se que as variáveis VAT e VADF estão muito altamente correlacionadas (0,95 e 0982, respectivamente) e as variáveis RL e RO estão altamente correlacionadas (0,782 e 0,707, respectivamente).

Contudo, nesta análise de correlação, especificamente com as variáveis VAT e VADF, há um viés que justifica a correlação quase perfeita. O viés compreende que alguns valores que estão na variável independente também fazem parte dos valores dessas variáveis dependentes. Como foi exposto na subseção 2.1, no ISI há os valores com alimentação, encargos sociais compulsórios, previdência privada, saúde, segurança e medicina no trabalho,

REUNIR - Revista de Administração, Contabilidade e Sustentabilidade - Vol. 1, nº 2, p.82-100, Set-Dez/2011. 
educação, cultura, capacitação e desenvolvimento profissional, creches ou auxílio-creche, participação nos lucros ou resultados e outros. E, no VAT, especificamente no VADF, há valores de remuneração paga líquido do encargo com INSS; benefícios como assistência médica, alimentação, transporte, planos de benefícios e FGTS.

Essa sobreposição de valores cria o viés que propicia a correlação quase perfeita. Entretanto, não foi possível eliminar esses valores, logo o efeito, pelo fato que nos BS e nas DVA coletadas os dados estavam sintetizados em uma única rubrica, e era necessário ter a rubrica segregada.

Assim, pode pressupor que haja uma correlação positiva entre o ISI e o VAT bem como o VADF, mas não tão forte como se apresenta, devido ao viés identificado. Esse viés não acontece com as variáveis RL e RO.

Em seguida foi realizada a regressão linear para determinar o efeito da mudança da variável ISI nas variáveis VAT, VADT, RL e RO. Por ser uma regressão linear simples, a correlação entre as variáveis é representada por R. O R ajustado $\left(\mathrm{R}^{2}\right)$ é interessante quando se aplica a regressão múltipla, para ter uma medida de variância explicada e assim obter uma estimativa mais realista e o erro padrão do quanto a estimativa pode estar correta (DANCEY e REIDY, 2006).

O modelo de regressão para a amostra pesquisada é apresentado na Tabela 3.

\begin{tabular}{cccccc}
\multicolumn{7}{c}{ Tabela 3: Modelo de Regressão } \\
\hline Variável Dependente & Modelo & $\mathbf{R}$ & $\mathbf{R}^{\mathbf{2}}$ & $\mathbf{R}^{\mathbf{2}}$ Ajustado & Erro Padrão da Estimativa \\
\hline VAT & 1 &, 950 &, 902 &, 900 & 2498675,636 \\
VADF & 2 &, 982 &, 965 &, 964 & 544798,479 \\
RL & 3 &, 782 &, 612 &, 604 & $1,309 \mathrm{E} 7$ \\
RO & 4 &, 707 &, 499 &, 490 & 2668594,203 \\
\hline
\end{tabular}

Nota. Variável independente: ISI

Fonte: dados da pesquisa, 2010.

Analisando a Tabela 3, observa-se que o R é de 0,950 para o VAT; 0,982 para o VADT; 0,782 para a RL e; 0,707 para a RO. O resultado dessas regressões explica quanto às variáveis dependentes são afetadas por alguma mudança na variável independente (ISI). O mesmo viés exposto na correlação existe na regressão. Assim, pode considerar que existe uma regressão entre o ISI e o VAT bem como o VADT, mas não tão elevada como se apresenta. Enquanto a correlação entre o ISI e a RL e a RO são mais fidedignas.

Na Tabela 4 são apresentados os coeficientes da regressão, onde B (coeficiente não padronizado) é a inclinação, isto é, o quanto a variável dependente variará para cada centavo de aumento no valor da variável independente (ISI) e; $\beta$ (coeficiente padronizado) indica o aumento nas variáveis dependentes quando se aumenta um desvio padrão na variável independente (ISI). Assim, $\beta$ é o coeficiente de que a inclinação da população pode ser encontrada entre o intervalo "limite inferior" e "limite superior" (DANCEY e REIDY, 2006). 
Tabela 4: Coeficientes da Regressão

\begin{tabular}{|c|c|c|c|c|c|c|c|c|}
\hline \multirow[b]{2}{*}{ Modelo } & & \multicolumn{2}{|c|}{$\begin{array}{l}\text { Coeficientes não- } \\
\text { padronizados }\end{array}$} & \multirow{2}{*}{$\begin{array}{c}\text { Coeficientes } \\
\text { Padronizados } \\
\beta\end{array}$} & \multirow[t]{2}{*}{ t } & \multirow[t]{2}{*}{ Sig. } & \multicolumn{2}{|c|}{$\begin{array}{c}\text { Intervalo de Confiança de } \\
95 \% \text { para B }\end{array}$} \\
\hline & & B & Erro Padrão & & & & $\begin{array}{l}\text { Limite } \\
\text { inferior }\end{array}$ & $\begin{array}{l}\text { Limite } \\
\text { Superior }\end{array}$ \\
\hline \multicolumn{9}{|c|}{ Dependente Variável: VAT } \\
\hline \multirow[t]{2}{*}{1} & Constante & 86585,931 & 574434,292 & &, 151 &, 881 & $-1066100,69$ & 1239272,69 \\
\hline & ISI & 5,134 & ,235 & ,950 & 21,838 &, 000 & 4,663 & 5,606 \\
\hline \multicolumn{9}{|c|}{ Dependente Variável: VADF } \\
\hline \multirow[t]{2}{*}{2} & Constante & 384259,99 & 125246,720 & & 3,068 & 003 & 132933,54 & 635584,916 \\
\hline & ISI & 1,931 & 051 & ,982 & 37,662 &, 000 & 1,828 & 2,034 \\
\hline \multicolumn{9}{|c|}{ Dependente Variável: RL } \\
\hline \multirow[t]{2}{*}{3} & Constante & $-687617,4$ & $\begin{array}{c}3008223,72 \\
3\end{array}$ & &,- 229 & 820 & $-6724059,9$ & $\begin{array}{l}5348825,14 \\
3\end{array}$ \\
\hline & ISI & $11,140 \mathrm{a}$ & 1,231 & ,782 & 9,047 &, 000 & 8,669 & $13,610 \mathrm{a}$ \\
\hline \multicolumn{9}{|c|}{ Dependente Variável: RO } \\
\hline 4 & Constante & 224098,62 & 613497,807 & &, 365 & ,716 & $-1006974,8$ & $\begin{array}{c}1455172,02 \\
9\end{array}$ \\
\hline & ISI & 1,808 &, 251 & ,707 & 7,200 & ,000 & 1,304 & 2,312 \\
\hline
\end{tabular}

Fonte: dados da pesquisa, 2010.

Desse modo, constata-se que para cada centavo de aumento de ISI todas as variáveis dependentes aumentarão: o VAT em R \$ 5,13; o VADF em R \$ 1,93; a RL em R\$ 11,14 e; a RO em R\$ 1,80 com 0,950;0,982;0,782 e; 0,707 de confiança, respectivamente. Embora, realizada a análise dos coeficientes de regressão ela é mais adequada quando utiliza a regressão múltipla. Além disso, o elevado coeficiente nas variáveis VAT e VADF pode ter o viés exposto acima.

Sumarizando, os resultados da análise da correlação e da regressão indicam que os ISI contribuem para a geração e distribuição de riqueza, bem como, a geração da receita líquida e operacional das organizações bancárias. Embora a amostra seja pequena é possível sugerir que esses resultados, com alguma variação, representem os resultados desse segmento econômico.

\section{CONSIDERAÇÕES FINAIS}

A responsabilidade social corporativa tem sido nas últimas décadas um tema considerado importante nas relações entre as organizações e a comunidade em geral, já que esta promove o crescimento empresarial e o desenvolvimento social. Além disso, a divulgação dos resultados dessa prática aos diversos usuários tem aumentado, principalmente desde a década de 1990, tendo como principais relatórios o BS e a DVA.

Ao analisar, comparativamente, a evolução dos investimentos sociais internos das organizações bancárias pesquisadas, pode-se concluir, pela análise horizontal, que o aumento de gastos com ISI também ocasiona aumento no VAT e no VADF para o Banrisul, a CEF, Banco Itaú e Banco Bradesco. Exceção ao Banco do Brasil, que apresentou uma média de crescimento, para o período, de $0,48 \%$ em ISI, entretanto teve uma queda de $3,73 \%$ em VADF. Por outro lado, o Banco Santander apresentou uma diminuição dos seus gastos com ISI, logo apresentou uma redução na geração e na distribuição da riqueza.

Entre os bancos analisados, conclui-se que o Banco Itaú, por apresentar o melhor 
desempenho na análise horizontal, é o banco que mais investe e mais gera riqueza. Entretanto, o Banco do Brasil é o banco que mais distribui riqueza por funcionário. Por outro lado, o Banrisul, pelas médias dos valores do período, é a instituição que menos investiu e que menos distribuiu riqueza aos seus funcionários.

Conclui-se, pela análise de correlação e regressão, que há uma correlação positiva e forte entre ISI e a geração e distribuição de riqueza, bem como de geração de receita líquida e operacional. Ainda a regressão indica que as variáveis dependentes (VAT, VADF, RO e RL) são afetadas pela variável independente (ISI). Assim, aumento nos gastos com ISI contribui para o aumento da riqueza gerada e da receita da organização.

Para futuras pesquisas, sugere-se a expansão da amostra e a aplicação deste estudo em outros segmentos econômicos, com novos cruzamentos de variáveis e uso de outras técnicas estatísticas, com o propósito de comparar com os resultados desta pesquisa, bem como ampliá-lo.

\section{REFERENCIAS}

BANCO BRADESCO. Relações com Investidores. Disponível em: http://www.bradescori.com.br. Acesso em: 14 ago. 2010. Link

BANCO BRADESCO. Banco do Planeta. Disponível em: http://www.bancodoplaneta.com.br. Acesso em: 14 ago. 2010. Link

BANCO CENTRAL DO BRASIL. 50 maiores bancos $e$ o consolidado do Sistema Financeiro Nacional. Disponível em: http://www4.bcb.gov.br/top50/port/top50.asp. Acesso em: 06 set. 2010. Link

BANCO DO BRASIL. Relações com Investidores. Disponível em: http://www.bb.com.br. Acesso em: 14 ago. 2010. Link

BANCO ITAÚ. Relações com Investidores. Disponível em: http://www.itau.com.br e Acesso em: 14 ago. 2010. Link

Relações com Investidores. Disponível em: http://www.itauunibanco.com.br.

Acesso em: 14 ago. 2010. Link

BANCO SANTANDER. Relações com Investidores. Disponível em: http://www.santander.com.br. Acesso em: 14 ago. 2010. Link

BANCO DO ESTADO DO RIO GRANDE DO SUL (BANRISUL). Relações com Investidores. Disponível em: http://www.banrisul.com.br. Acesso em: 14 ago. 2010. Link

BERTAGNOLLI, Daniele Dias de Oliveira; OTT, Ernani; DAMACENA, Cláudio. Estudo sobre a Influência dos Investimentos Sociais e Ambientais no Desempenho Econômico das empresas. In: CONGRESSO DE CONTROLADORIA E CONTABILIDADE DA USP, 6 , 2006. São Paulo. Anais... São Paulo/SP: USP, 2006. Disponível em: http://www.congressousp.fipecafi.org/artigos62006/548.pdf. Acesso em: 10 mai. 2010. Link

REUNIR - Revista de Administração, Contabilidade e Sustentabilidade - Vol. 1, nº 2, p.82-100, Set-Dez/2011 
BISPO, Jorge de Souza. Criação e distribuição de riqueza pela Zona Franca de Manaus. 2009. Tese (Programa de Pós Graduação em Controladoria e Contabilidade), Universidade de São Paulo, São Paulo, 2009, p. 317.

BISQUERRA, Rafael; SARRIERA, Jorge Castellá; MARÍNEZ, Francesc. Introdução à estatística: enfoque informático como pacote estatístico SPSS. Porto Alegre: Artmed, 2004. $255 \mathrm{p}$.

CAIXA ECONOMICA FEDERAL. Downloads - Arquivos por assunto: a Caixa. Disponível em: http://www1.caixa.gov.br/download/index.asp. Acesso em: 14 ago 2010. Link

CERVO, Amado Luiz; BERVIAN, Pedro Alcino. Metodologia Científica. 5. ed. São Paulo: Prentice Hall, 2002.

COMITÊ DE PRONUNCIAMENTOS CONTÁBEIS (Brasil). CPC 09 - Demonstração do Valor Adicionado. 2008. Disponível em: http://www.cpc.org.br. Acesso em: 05 jun. 2010. $\underline{\text { Link }}$

CUNHA, Jacqueline Veneroso Alves da. Demonstração Contábil do Valor Adicionado DVA - um instrumento de mensuração da distribuição da riqueza das empresas para os funcionários. 2002. Dissertação (Programa de Pós Graduação em Controladoria e Contabilidade), Universidade de São Paulo, São Paulo, 2002, p. 255.

DANCEY, Christine P.; REIDY, John. Estatística sem matemática para psicologia. Porto Alegre: Artimed, 2006.

FREGONESI, Mariana Simões Ferraz do Amaral. Investimentos socioambientais na Demonstração do Valor Adicionado: formação ou distribuição do valor adicionado? 2009. Tese (Programa de Pós Graduação em Controladoria e Contabilidade), Universidade de São Paulo, São Paulo, 2009, p. 229.

GIL, Antônio Carlos. Como elaborar projetos de pesquisa. 4 ed. São Paulo: Atlas, 2002.

INTERNATIONAL ACCOUNTING STANDARDS BOARD (IASB). Standards (IFRSs). Disponível em: http://www.ifrs.org/IFRSs/IFRS.htm. Acesso em: 29 nov. 2011. Link

IUDÍCIBUS, Sérgio de; MARTINS, Eliseu; GELBCKE, Ernesto Rubens; SANTOS, Ariovaldo dos. Manual de Contabilidade Societária. São Paulo: Atlas, 2010.

KROETZ, Cesar Eduardo Stevens. Balanço Social: teoria e prática. São Paulo: Atlas, 2000.

LEITE FILHO, Geraldo Alemandro; FIGUEIREDO, Sérgio Ramos de. Relação entre o EVA $^{\circledR}$ e os Investimentos em Responsabilidade Social empresarial das instituições bancárias do Brasil. RIC: Revista de Informação Contábil, v. 3, n. 4, p. 22-43, Out-Dez/2009. Disponível em: http://www.ufpe.br/ricontabeis/index.php/contabeis/article/view/190/158. Acesso em: 10 mai. 2010. Link

REUNIR - Revista de Administração, Contabilidade e Sustentabilidade - Vol. 1, nº 2, p.82-100, Set-Dez/2011. 
MACHADO, Márcia Reis; MACHADO, Márcio André Veras; SANTOS, Ariovaldo. A relação entre o setor econômico e investimentos sociais e ambientais. In: CONGRESSO DE CONTROLADORIA E CONTABILIDADE DA USP, 9, 2009. São Paulo. Anais... São Paulo/SP: $\quad 2009 . \quad$ USP, Disponível em: http://www.congressousp.fipecafi.org/artigos92009/150.pdf. Acesso em: 10 mai. 2010. Link

MARCONI, Marina de Andrade; LAKATOS, Eva Maria. Técnicas de pesquisa. 5. ed. São Paulo: Atlas, 2002.

MILANI FILHO, Marco Antonio Figueiredo. Responsabilidade Social e Investimento Social Privado: entre o discurso e a evidenciação. In: CONGRESSO DE CONTROLADORIA E CONTABILIDADE DA USP, 7, 2007. São Paulo. Anais... São Paulo/SP: USP, 2007. Disponível em: http://www.congressousp.fipecafi.org/artigos72007/24.pdf. Acesso em: 10 mai. 2010. Link

REIS, Carlos Nelson dos; MEDEIROS, Luiz Edgar. Responsabilidade social das empresas e balanço social: meios propulsores do desenvolvimento econômico e social. São Paulo: Atlas, 2007.

SANTOLIN, Adriano Domingues; FREY, Márcia Rosane. O papel do Balanço Social na gestão empresarial. Contabilidade Vista \& Revista, Belo Horizonte, v. 16, n. 2, p. 61-81, $\mathrm{Ago} / 2005$. Disponível em: http://www.face.ufmg.br/revista/index.php/contabilidadevistaerevista/article/view/278. Acesso em: 10 mai. 2010. Link

SANTOS, Ariovaldo dos. Demonstração do Valor Adicionado: como elaborar e analisar a DVA. São Paulo: Atlas, 2003.

SANTOS, José Luiz dos; SCHMIDT, Paulo; MARTINS, Marco Antonio. Fundamentos de Análise das Demonstrações Contábeis. São Paulo: Atlas, 2006.

SCHEIBE, Margarete Lernen; SOUTES, Dione Olesczuk. Responsabilidade Social: um estudo de caso em uma cooperativa paranaense. In: CONGRESSO USP DE INICIAÇÃO CIENTÍFICA EM CONTABILIDADE, 5, 2008. Anais... São Paulo/SP: USP, 2008. Disponível em: http://www.congressousp.fipecafi.org/artigos82008/105.pdf. Acesso em: 10 mai. 2010. Link

SOARES, Sandro Vieira; LANZARIN, Jovani; CASAGRANDE, Maria Denise Henrique. Análise estatística do modelo IBASE de balanço social de uma empresa do setor de siderurgia. Revista Enfoque Reflexão Contábil. Maringá, Universidade Estadual de Maringá, v. 29 , n. 2 p. 27-39, maio/ago. 2010.

SOUZA, Diocesar Costa de; PACHECO, Vicente. O Balanço Social atende aos objetivos a que se propõe? In: CONGRESSO DE CONTROLADORIA E CONTABILIDADE DA USP, 7, 2007. São Paulo. Anais... São Paulo/SP: USP, 2007. Disponível em: http://www.congressousp.fipecafi.org/artigos72007/123.pdf. Acesso em: 10 mai. 2010. Link

REUNIR - Revista de Administração, Contabilidade e Sustentabilidade - Vol. 1, nº 2, p.82-100, Set-Dez/2011. 
TINOCO, João Eduardo Prudêncio. Balanço Social: uma abordagem da transparência e da responsabilidade pública das organizações. São Paulo: Atlas, 2001.

TORRES, Ciro; MANSUR, Claudia. Balanço Social, dez anos: o desafio da transparência. Rio de Janeiro: IBASE, 2008. Disponível em: http://www.ibase.br. Acesso em: 05 jun. 2010. $\underline{\text { Link }}$ 